\title{
Clinical, Morphological, and Biochemical Alterations in Acute Intestinal Yersiniosis
}

\author{
E. V. O'LOUGHLIN, G. HUMPhREYS, I. DUNN, J. KELLY, C. J. LIAN, C. PAI, AND \\ D. G. GALL \\ Intestinal Disease and Infectious Disease Research Units, Health Science Centre, The University of Calgary, \\ Calgary, Alberta, Canada
}

\begin{abstract}
The aim of this study was to examine the intestinal response to Yersinia enterocolitica (YE) infection. Growing New Zealand white rabbits (450-800 g) were infected with $10^{10}$ organisms of a human pathogenic strain $(n=43)$ or $\mathrm{NaHCO}_{3}$ for controls $(n=30)$ and studied $3,6,10$, and 14 days after infection. In a separate experiment infected $(n=6)$ and pair-fed controls $(n=6)$ were studied 6 days after infection. Weight gain, excretion of YE, and diarrhea were examined daily. At sacrifice segments of proximal and mid- and distal small intestine, cecum, and colon were obtained for histologic examination and mucosa of small intestine and colon for enzyme determinations. Infection with $\mathrm{YE}$ resulted in weight loss and diarrhea within 48-72 h. Microabscesses were present in all sections of small and large intestine by day 3 but became more severe in the ileocecal region by day 6 . In infected animals at day 6 there was crypt hyperplasia throughout the small intestine and villus atrophy in the ileum. Disaccharidases were decreased in all regions by day 3 but returned to normal by day 14 in proximal and mid-, but not distal, small intestine. The pair-fed controls experienced a similar weight loss to infected animals, but showed only minor morphologic changes and no mucosal enzyme abnormalities. Our findings demonstrate that infection of weanling rabbits with $\mathrm{YE}$ causes diarrhea and weight loss and that, while the weight loss is largely due to reduced food intake, the morphologic and mucosal enzyme alterations are due to intestinal injury by the organism. (Pediatr Res 20: 602-608, 1986)
\end{abstract}

Abbreviation

\section{YE, Yersinia enterocolitica}

Bacterial enteritis is a common problem in infancy and childhood. YE is recognized as a major cause of bacterial enteritis in the pediatric population (1-3). Clinical presentation may vary from acute gastroenteritis or appendicitis to a chronic relapsing ileocolitis (1). YE may also be associated with septicemia, liver abscesses, and extraintestinal manifestations such as arthritis, erythema nodosum (1), and glomerulonephritis (4).

Although the invasive capacity of $\mathrm{YE}$, which is associated with a 42-48 megadalton plasmid, is essential for virulence $(5,6)$,

Received October 4, 1985; accepted February 18, 1986.

Address reprints and correspondence to D. Grant Gall, M.D. Department of Pediatrics, Health Science Centre, 3330 Hospital Drive N.W., Calgary, Alberta, T2N 4N1 Canada.

This work was supported by the Medical Research Council of Canada. E.V.O'L. and I.D were the recipients of Alberta Heritage Foundation for Medical Research Fellowships. little is known about the underlying pathophysiology that leads to diarrhea. The aim of the present study was to examine the intestinal response to experimental Yersiniosis in growing rabbits in an attempt to define the mechanisms of diarrhea.

\section{METHODS}

Bacterial strain. YE strain MCH 700S (serotype 0:3), originally isolated from a patient with diarrhea, was used. The in vivo and in vitro virulence properties of the strain, which possesses a 42 megadalton plasmid, have been previously described (7-9). Stock culture was stored at $-70^{\circ} \mathrm{C}$ in brain-heart perfusion broth with $20 \%$ glycerol. For preparation of the inoculum for experimental infection, bacteria were inoculated onto sheep blood agar plates directly from the stock culture and grown overnight at room temperature.

Model. Weanling New Zealand white rabbits weighing 450 $800 \mathrm{~g}$ were studied. Animals were initially observed for 3 to 4 days to ensure the absence of diarrhea. Then after an overnight fast animals were infected $(n=43)$ with the YE strain by intragastric inoculation of $1 \times 10^{10}$ colony forming units suspended in $10 \mathrm{ml} \mathrm{NaHCO}$ as previously described (9). Controls $(n=30)$ received $10 \mathrm{ml} \mathrm{NaHCO}_{3}$ only.

Experimental design. Weight gain, excretion of YE, and evidence of diarrhea were assessed daily. Rabbits were considered to have diarrhea if their perinei or hind legs were soiled. Daily rectal swabs were plated onto Salmonella-Shigella media for YE isolation. Animals were sacrificed at 3, 6, 10, and 14 days postinoculation by cervical dislocation. In a second experiment, infected $(n=6)$ and control $(n=6)$ animals were paired on the basis of age and weight. Food intake of the infected animals was recorded and fed to each paired $\mathrm{NaHCO}_{3}$ inoculated control Unmanipulated controls $(n=6)$ of similar age and weight were compared to the infected and pair-fed control animals. Animals were followed as described above and studied 6 days after infection.

Morphologic and cell kinetic studies. On the day of study histologic sections were taken from proximal, mid-, and distal small intestine, cecum, proximal colon, Peyer's patches, appendix, mesenteric lymph nodes, and liver. Sections were fixed in $4 \%$ phosphate buffered formalin, dehydrated, embedded in paraffin wax, sectioned, and stained with hemotoxylin and eosin or methylene blue and basic fuchsin.

In a separate group of animals sections for radioautography and morphometry were obtained from control $(n=3)$, pair-fed control $(n=4)$, and infected $(n=4)$ animals. These animals were injected with $1 \mu \mathrm{Ci} / \mathrm{g}$ body weight $\left[{ }^{3} \mathrm{H}\right]$ thymidine intravenously 6 days after infection and sacrificed $1 \mathrm{~h}$ later. Sections from proximal, mid-, and distal small intestine were removed, fixed in phosphate buffered formalin, and embedded in glycol methacrylate. One $-\mu$ sections were cut and prepared for radioautography as previously described (10). After development and 
fixation of photographic emulsion, sections were stained with methylene blue and basic fuchsin. Sections for morphometric studies were prepared in the same manner with the exclusion of radioautographic development.

Villus height and crypt depth were measured on at least 10 well-oriented villus-crypt units per segment by calibrated micrometer. Radiolabeled uptake was assessed in 10-15 well-oriented crypts. The crypt base was identified by the presence of

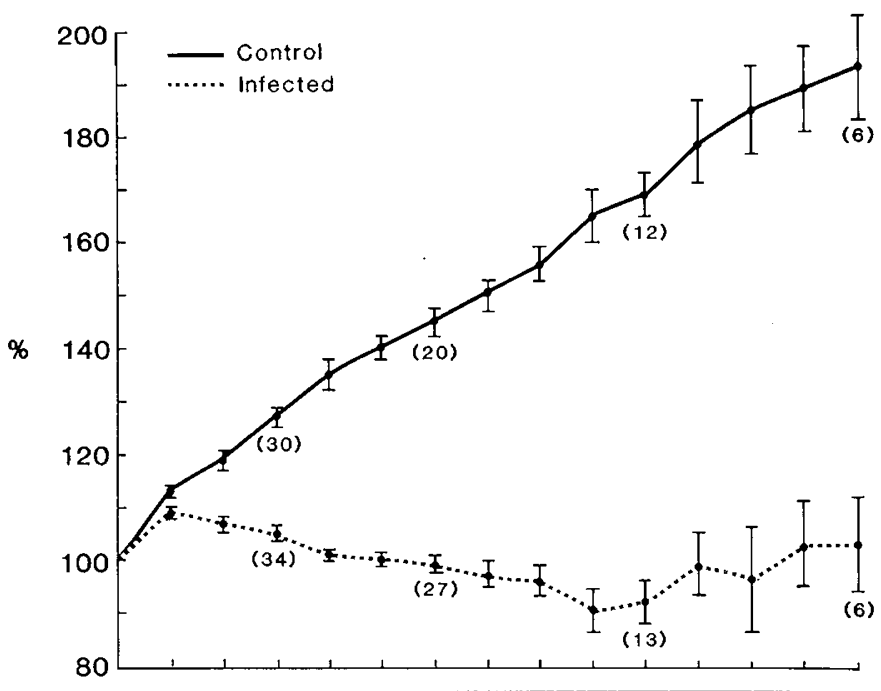

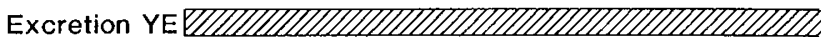

Diarrhea

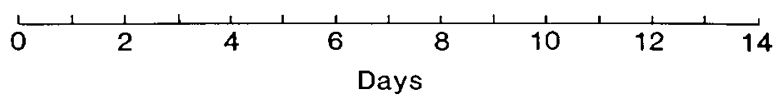

Fig. 1. Clinical data from the longitudinal study depicting animal weight as a percentage of weight on day 0 (inoculation), stool excretion of $Y E$ and presence of diarrhea. Values are mean $\pm \mathrm{SE}$ and numbers in parentheses represent numbers of animals followed to that day.
Paneth cells and radiolabeled nuclei counted and the position of the labeled cells recorded for each crypt column. Nuclei with at least 6 overlying grains were considered to have incorporated the label. The number of crypt cells per column, height of the leading edge (highest cell to incorporate the label) and labeling index (\% of crypt cells incorporating the label) were determined (10).

Mucosal enzyme activities. Mucosa, from proximal, mid-, and distal small intestinal segments and colon, was scraped with a glass slide, homogenized in $2.5 \mathrm{mM}$ EDTA, and frozen at $-70^{\circ}$ $\mathrm{C}$ until analyzed for enzyme activities. Sucrase and maltase were measured according to the method of Dahlqvist (11), $\mathrm{Na}^{+} \mathrm{K}^{+} \mathrm{ATPase}$ by the method of Kelly et al. (12) and thymidine kinase by the method of Klemperer and Haynes (13). Protein was measured by the method of Lowry et al. (14) and enzyme activities expressed as $\mathrm{U} / \mathrm{mg}$ or $\mathrm{g}$ protein.

Values are expressed as mean \pm SEM and means compared by Student's $t$ test.

\section{RESULTS}

Longitudinal Study. Clinical. Forty-three rabbits with a mean weight of $567 \pm 20 \mathrm{~g}$ were infected with YE. Nine rabbits died producing an overall mortality of $21 \%$. Mortality increased with increasing duration of disease; one died on day 6 , two died on day 7 , one on day 9 , one on day 10 , and four between days 12 and 14. Data from these animals are not included in the analysis. Thirty control animals, mean weight $537 \pm 14 \mathrm{~g}$, were studied and none died.

Cumulative clinical data are presented in Figure 1. Control animals gained weight and achieved $190 \%$ of starting weight by day 14 while infected animals lost weight from days 2 to 9 and by day 14 had failed to gain weight. Yersinia was isolated from the stool by $48 \mathrm{~h}$ in all infected animals and diarrhea developed between 3 and 4 days. Positive cultures and diarrhea persisted for the duration of the disease. No animals exhibited blood in their stool.

Pathology. On gross inspection the cecum was dilated and fluid filled and the terminal ileum and proximal colon were hyperemic and fluid filled. Small abscesses were visible through

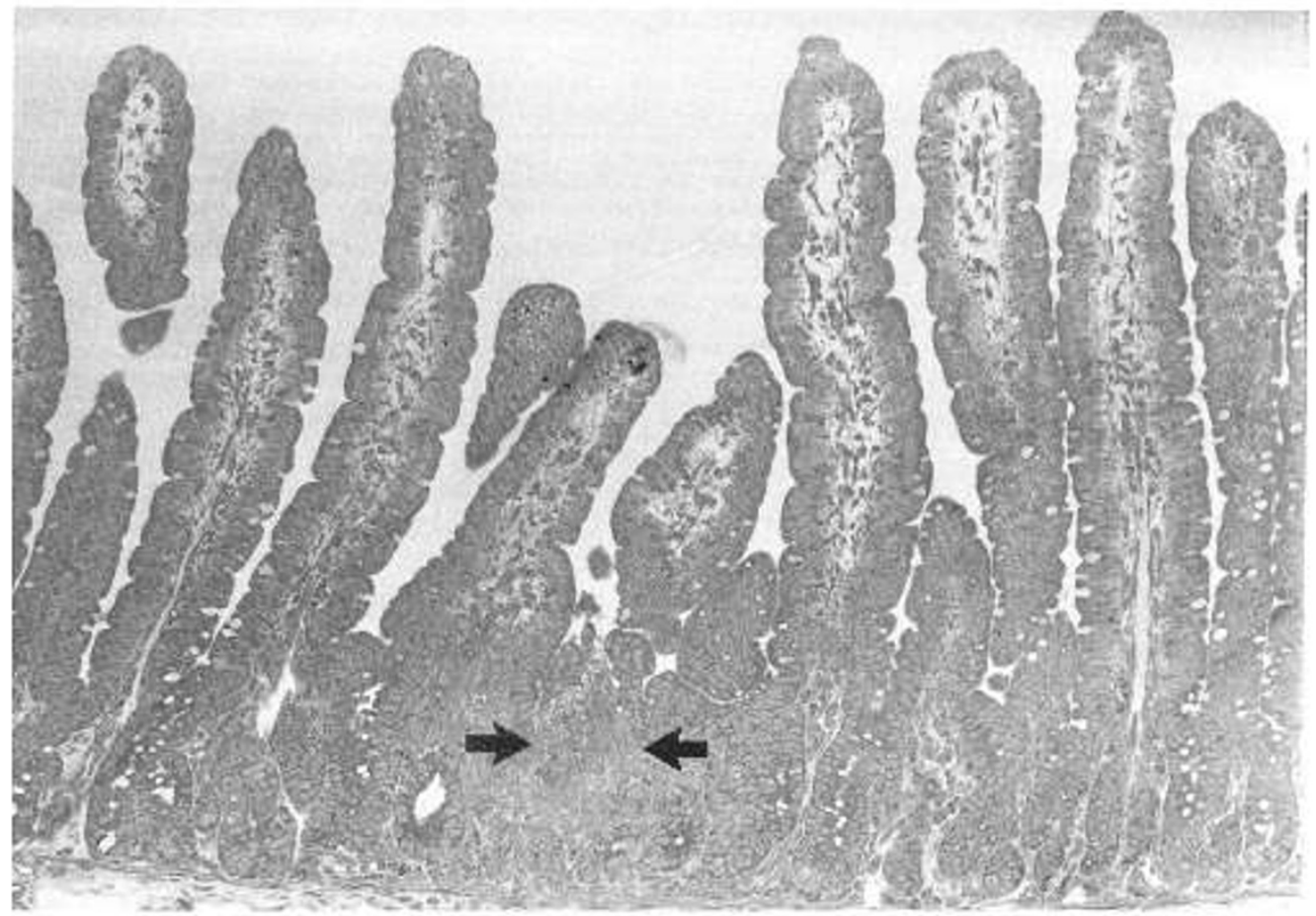

Fig. 2. Section from mid-small intestine demonstrates shortening of the central villi overlying a microabscess which is indicated by the arrows. Adjacent villi are of normal height and appearance. (Methylene Blue and Basic Fuchsin, $\times 155$.) 
the serosa of cecum, Peyer's patches, and appendix. Microscopic examination of colonic fluid revealed neutrophils and red blood cells.

On day 3 histologic sections from all areas of the small intestine demonstrated microabscesses surrounding bacteria in the lamina propria of the crypt region (Figs. 2 and 3 ). Bacteria were only seen in the lamina propria adjacent to crypts. They were not seen in villi or adhering to enterocytes (Fig. 3). The abscesses were patchy in distribution and appeared to preferentially arise on the apices of mucosal folds where they surrounded and destroyed crypts. The overlying villi were shortened and distorted and the abscesses sometimes caused small ulcers (Fig. 3). Adjacent villi appeared normal (Fig. 2). In the cecum and colon abscesses also tended to be patchy in distribution, to develop around crypt bases, and to more frequently result in ulcer formation (Fig. 4). In both small and large intestine inflammatory infiltrate occasionally extended through the muscularis mucosa but not into the muscularis propria. This was particularly evident in the cecum. By day 6 , while the morphologic changes were still apparent throughout the intestine, they were most extensive in the ileum and cecum.

YE appeared to have a predilection for invasion into Peyer's patches and appendix. Typical lesions are seen in Figure 5. Abscesses were present under the dome epithelium and in germinal centers. In the appendix, abscesses were present in the

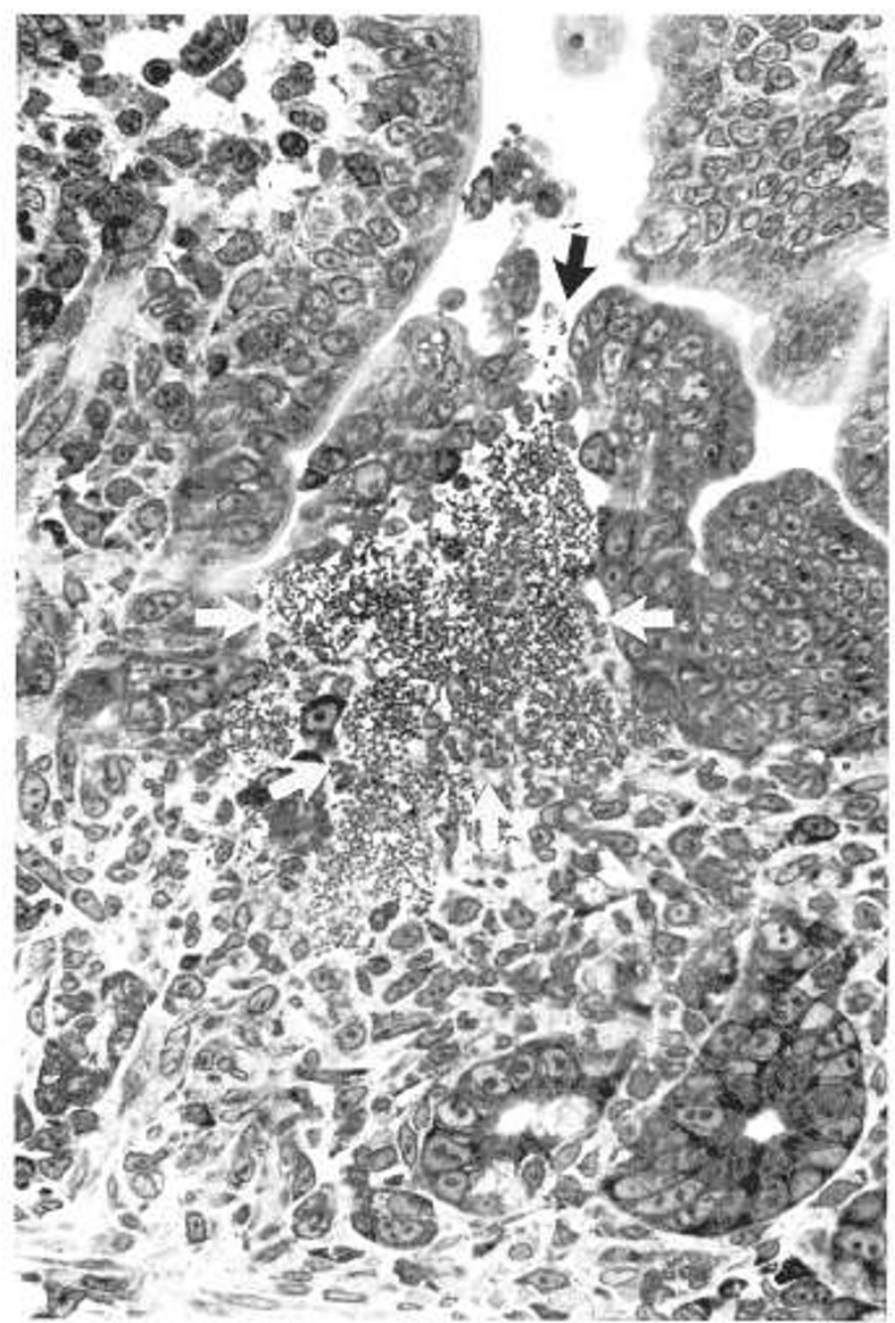

Fig. 3. A higher magnification of the area indicated by the arrows in Figure 2 displays an early microabscess containing a large colony of bacteria in the superficial lamina propria (white arrows) together with a focal breach of the overlying epithelium (black arrow). (Methylene Blue and Basic Fuchsin, $\times 620$.) majority of germinal centers by day 10 resulting in destruction and involution of the lymphoid tissue.

Granuloma were present in the liver by day 6 and by day 14 there were frequent microabscesses and occasional macroscopic abscesses present. Draining mesenteric lymph nodes showed evidence of granulomas and the occasional microabscesses by day 6 .

Mucosal enzymes. Mucosal brush border enzymes are depicted in Figure 6. In infected animals sucrase and maltase activity were significantly decreased in all areas by day 3 , remained depressed until day 10 , and then returned to normal by day 14 in the proximal and mid-segments. In the ileum sucrase activity remained depressed throughout the study period. Maltase activity was also reduced and followed a similar pattern.

Pair-Feeding Study. Clinical. Since infection with YE inhibited growth (Fig. 1) a second experiment involving pair-feeding was carried out to assess the impact of malnutrition during infection.

Weight gain was significantly less by day 2 in both pair-fed and infected animals compared to controls (Fig. 7). Food intake in infected animals $(16.3 \pm 5.2 \mathrm{~g} /$ day $)$ decreased to one-third of control values $(50.0 \pm 3.6 \mathrm{~g})$ by the end of the study period. Neither infected nor pair-fed animals gained weight by day 6 and mean weights were not significantly different. Excretion of $\mathrm{YE}$ in the stool and onset of diarrhea again occurred on days 2 and 3 , respectively.

Morphometry and cell kinetic studies. Villus height was unaffected by infection or reduced food intake in the proximal or mid-small bowel (Fig. 8). In the ileum there was a slight, but significant, decrease of villus height in pair-fed and to a greater degree in infected animals compared to controls. Reduced food intake alone decreased crypt depth compared to control values in all small intestinal segments (proximal and mid-, $p<0.05$; ileum, $p=0.07$ ). In infected animals crypt depth was significantly increased compared to pair-fed animals in the proximal and midsections and to both pair-fed and control animals in the ileum.

Cell turnover was assessed by counting the number of cells per crypt column and the uptake of $\left[{ }^{3} \mathrm{H}\right]$ thymidine into dividing nuclei (Table 1). The number of cells per crypt column was significantly decreased in all regions in the pair-fed animals compared to controls. In contrast, crypt cell number in infected animals did not differ from control values but was significantly increased in all regions compared to pair-fed animals. In the pair-fed group there was also a tendency to a contracted proliferative column (height of leading edge of label); this reached statistical significance in the mid-small intestine. In contrast, infection induced a significant increase in height of the proliferative compartment in all segments compared to pair-fed animals. The labeling index (\% of crypt cells incorporating the label) was significantly increased in the ileum in infected animals compared to both control groups which were not different.

Mucosal enzymes. In the pair-fed animals reduced food intake alone did not significantly alter mucosal enzyme activities (Table 2). Infection resulted again in a marked decrease in sucrase and maltase activities, and significantly increased $\mathrm{Na}^{+} \mathrm{K}^{+}$ATPase activity in all regions of the small intestine compared to both pairfed and control groups. Thymidine kinase activity was unchanged in proximal and mid-segments but was significantly increased in the ileum compared to pair-fed and controls which were not different. In the colon $\mathrm{Na}^{+} \mathrm{K}^{+}$TATPase and thymidine kinase activities were not altered by infection or pair feeding.

\section{DISCUSSION}

This study correlates clinical, morphologic, biochemical, and cell kinetic observations in an animal model of infectious diarrhea which closely resembles human Yersiniosis. Although we used a plasmid-containing, serotype $0: 3$ strain of $\mathrm{YE}$, the data from this study should be applicable to YE gastroenteritis in general, since a common property of all virulent $\mathrm{YE}$ strains is 


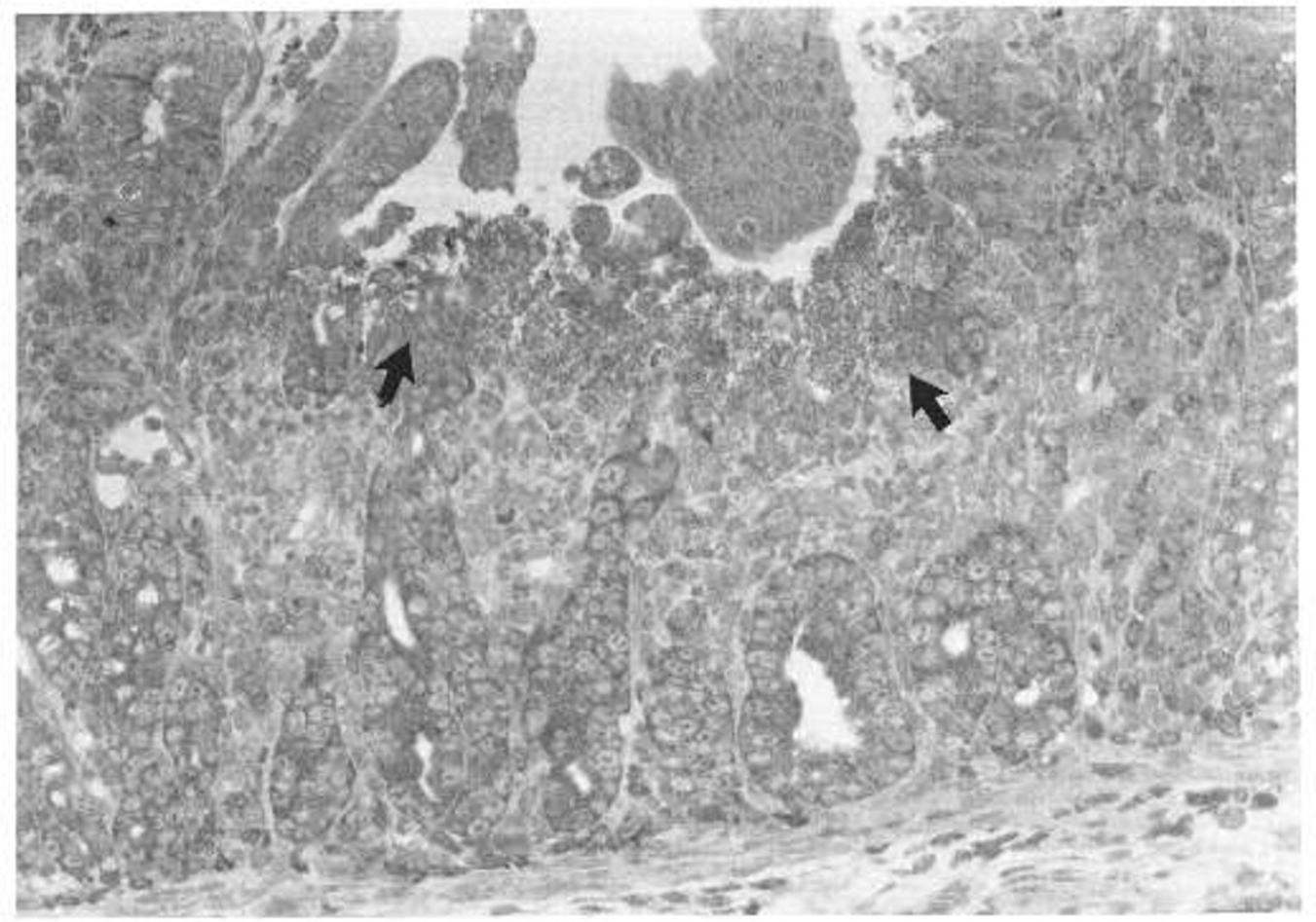

Fig. 4. Section from proximal colon demonstrating an ulcer (arrows). Methylene Blue and Basic Fuchsin, $\times 325$.)

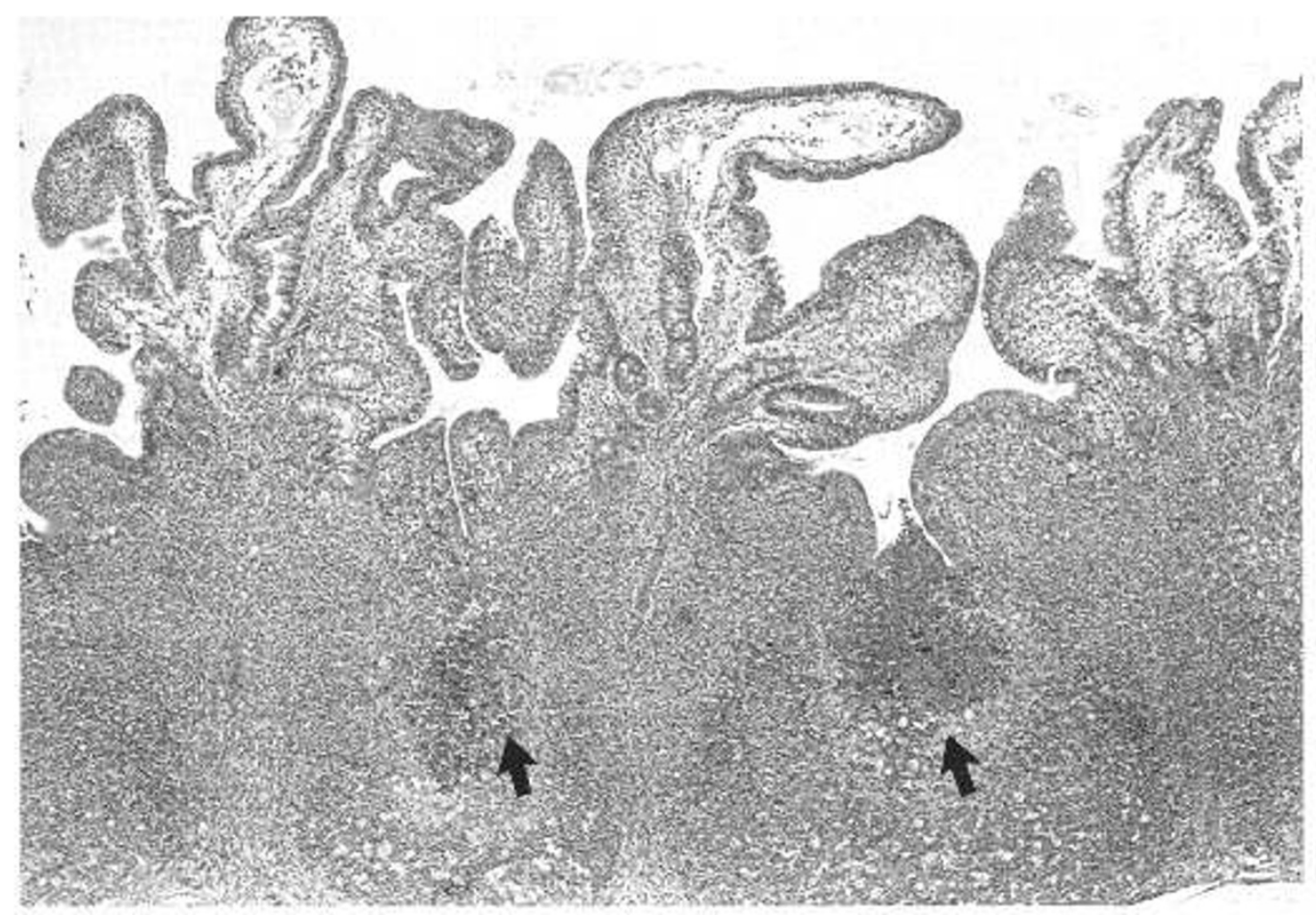

Fig. 5. Sections from a proximal Peyer's patch demonstrating an ulcerating abscess on the dome epithelium on the right (arrow) and an abscess extending into the germinal center on the left (arrow). Hematoxylin and eosin, $\times 65$.)

possession of the virulence plasmid $(5,6)$. Weanling rabbits infected with a human pathogenic strain of YE develop a reproducible and consistent infection. The disease is characterized by weight loss and diarrhea and is associated with marked histologic and biochemical changes in the intestinal mucosa. Stool excretion of $\mathrm{YE}$ was present by $48 \mathrm{~h}$ after infection and continued in all animals for the course of the disease. Weight loss, reduced food intake, and diarrhea were also apparent by $48-72 \mathrm{~h}$ after infection (Fig. 1).
The histologic appearances are similar to those previously described in rabbits (9) and monkeys (15) with YE infection but differed from those described in mice (16). Mice develop invasive disease in Peyer's patches and appendix sparing absorptive epithelia in both small and large intestine. While there appears to be species variation, the rabbit model displays a number of similarities to abnormalities reported in human infection. These include: Extensive mucosal abscess formation and occasional ulcer formation in absorptive epithelium; localization of the 


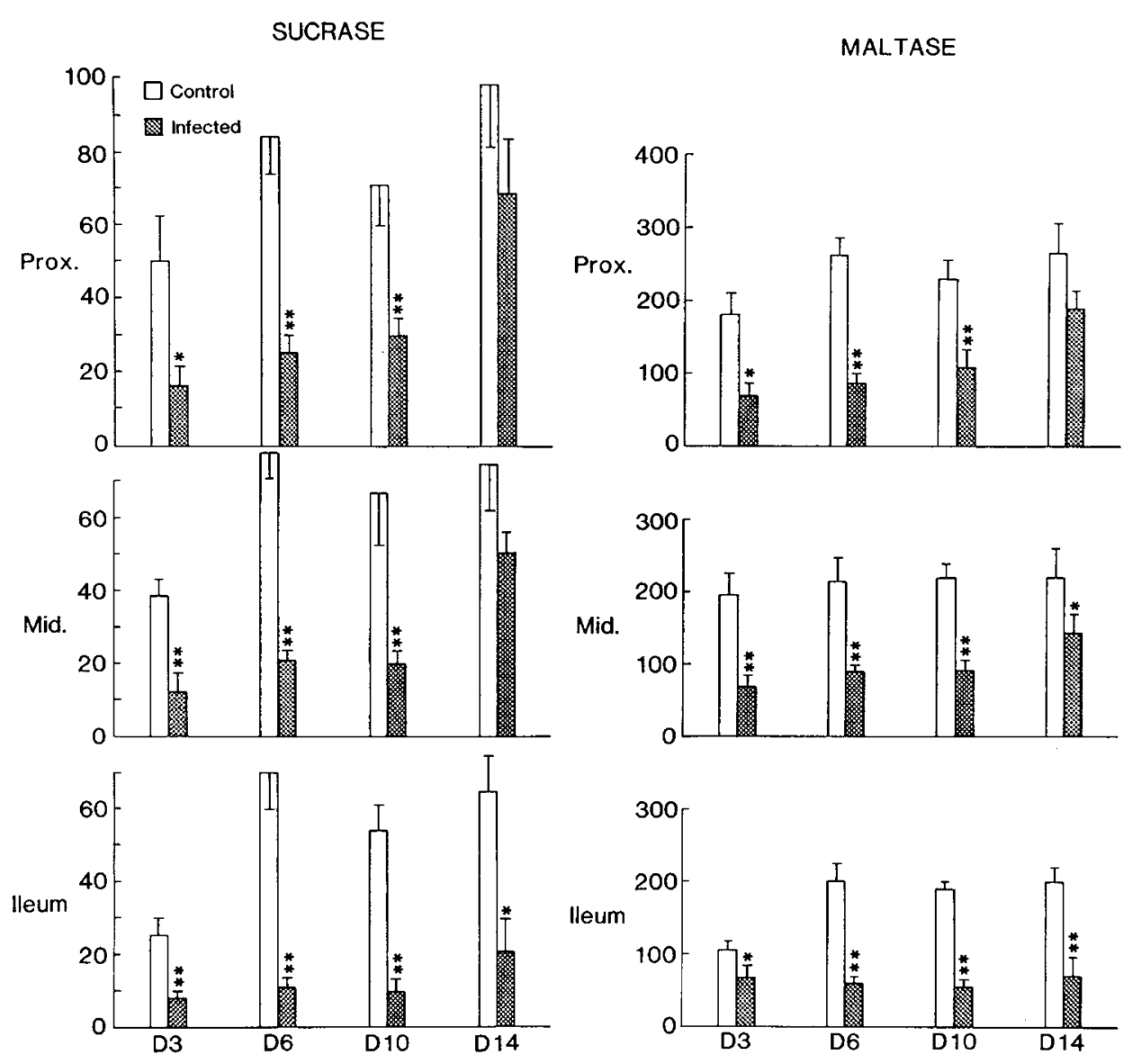

Fig. 6. Mucosal sucrase and maltase activities from proximal and mid small intestine and ileum 3,6,10, and 14 days after inoculation. Values are mean \pm SE and are expressed as units per g protein. ${ }^{*} p<.05,{ }^{* *} p<0.01$ compared to control values.

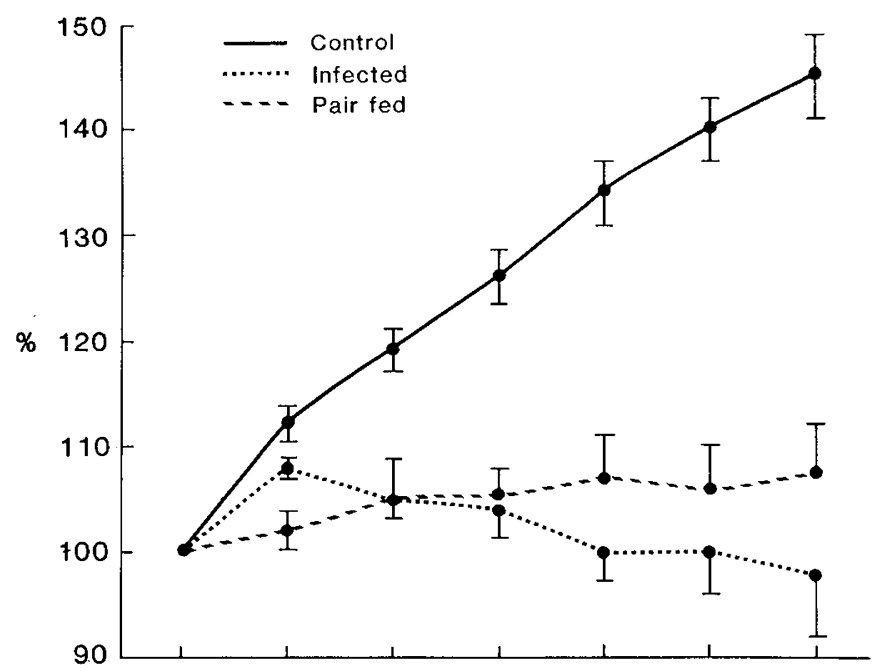

Excretion Y.E. WOIIIIIIIIIIIIIIIIIA

\section{Diarrhea}

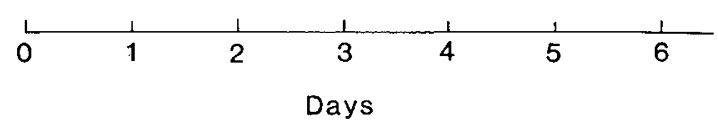

Fig. 7. Clinical data from the pair-feeding study depicting animal weight as a percentage of weight on day 0 (inoculation), stool excretion of $Y E$, and presence of diarrhea. Values are mean $\pm S E$.

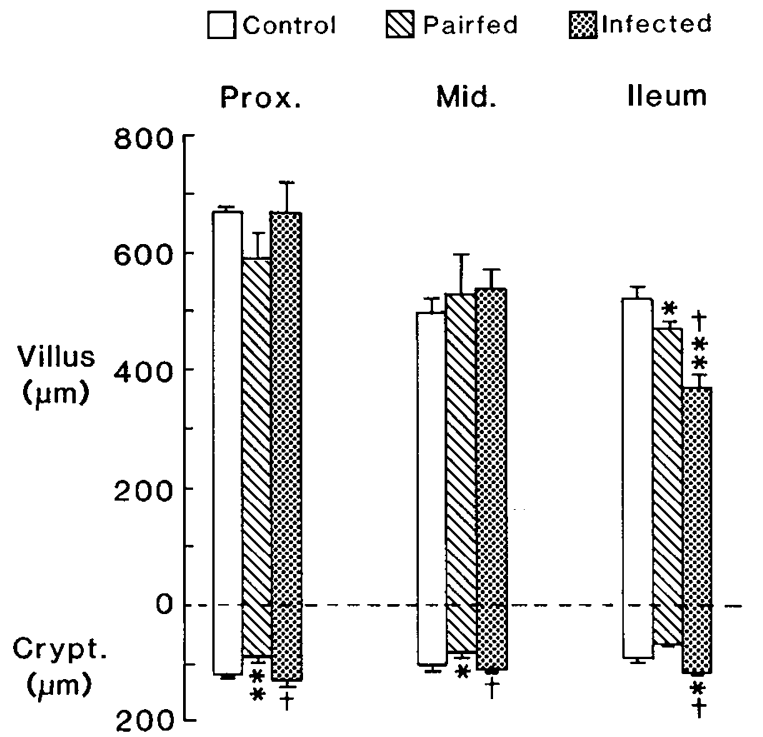

Fig. 8. Villus height and crypt depth in small intestinal segments. Values are mean $\pm \mathrm{SE} .{ }^{*} p<0.05,{ }^{* *} p<0.01$ compared to control and $+p<0.01$ compared to pair fed.

disease to the ileocecal region later in the disease; extensive invasion of Peyer's patches and appendix; spread to the mesenteric lymph nodes (17); and the presence of hepatic disease characterized by granuloma (18) and abscess formation (19). 
Also YE infection resulted in a diffuse and severe small intestinal brush border injury. The brush border injury improved in the upper intestine as the disease progressed, but in keeping with histologic and morphometric findings, persisted in the ileum.

Infection with YE resulted in a marked decrease in food intake which appeared to account for the lack of weight gain (Figs. 1 and 7). Since severe protein-calorie malnutrition causes intestinal mucosal atrophy, decreased mitotic activity (20) and alterations in brush border enzymes (21), a pair-fed control group was examined. These animals were studied 6 days after infection because diarrhea and brush border enzyme changes are well established at this time. The reduced food intake in the pair-fed animals resulted in only minor changes. There was mild villus atrophy in the ileum, reduced crypt depth in all regions, and a diminished proliferative zone in the mid-small intestine. Mucosal enzyme activities were not altered in any region.

Infection with $Y E$ resulted in quite different changes. Despite the reduced food intake both crypt depth and the crypt proliferative compartment were increased compared to pair-fed animals. The findings of normal villus length but increased crypt proliferation in the proximal and mid-segments suggests increased cell turnover in these regions. The changes in the ileum were more dramatic. Villus atrophy was present to a greater degree than that seen in pair-fed controls and there was a greater increase in

Table 1. Crypt cell kinetics ${ }^{a}$

\begin{tabular}{|c|c|c|c|c|}
\hline & & Cells/crypt column & Leading edge $^{b}$ & Labeling index ${ }^{c}$ \\
\hline Proximal & $\begin{array}{l}\mathrm{C} \\
\mathrm{PF} \\
\mathrm{I}\end{array}$ & $\begin{array}{l}23.0 \pm 0.1 \\
18.5 \pm 0.7\left(^{*}\right) \\
23.0 \pm 1.5(\ddagger)\end{array}$ & $\begin{array}{l}14.5 \pm 2.0 \\
12.3 \pm 1.3 \\
17.6 \pm 2.4(\dagger)\end{array}$ & $\begin{array}{l}31.0 \pm 7.0 \\
28.8 \pm 5.0 \\
23.5 \pm 3.3\end{array}$ \\
\hline Mid & $\begin{array}{l}\mathrm{C} \\
\mathrm{PF} \\
\mathrm{I}\end{array}$ & $\begin{array}{l}20.7 \pm 1.3 \\
15.0 \pm 0.7\left({ }^{* *}\right) \\
21.0 \pm 0.4(\ddagger)\end{array}$ & $\begin{aligned} 16.6 & \pm 2.1 \\
9.5 & \pm 0.9\left(^{*}\right) \\
16.0 & \pm 1.0(\ddagger)\end{aligned}$ & $\begin{array}{l}29.7 \pm 3.2 \\
25.8 \pm 2.8 \\
32.0 \pm 2.9\end{array}$ \\
\hline Ileum & $\begin{array}{l}\mathrm{C} \\
\mathrm{PF} \\
\mathrm{I}\end{array}$ & $\begin{array}{l}19.0 \pm 2.1 \\
15.0 \pm 0.7(*) \\
19.4 \pm 0.7(\ddagger)\end{array}$ & $\begin{aligned} 10.0 & \pm 2.3 \\
9.8 & \pm 1.0 \\
13.8 & \pm 0.5(\ddagger)\end{aligned}$ & $\begin{array}{l}18.3 \pm 3.3 \\
23.0 \pm 1.1 \\
29.5 \pm 2.0(\dagger, *)\end{array}$ \\
\hline
\end{tabular}

${ }^{a}$ Crypt cell kinetics were determined 6 days after inoculation in $\mathrm{C}$ (control), PF (pair fed), and I (infected) animals. Values are mean \pm SE.

${ }^{b}$ Highest cell in column incorporating $\left[{ }^{3} \mathrm{H}\right]$ thymidine label.

${ }^{c}$ Percentage of crypt cells incorporating label.

${ }^{*} p<0.05, * *<0.01$ compared to controls; $\uparrow p<0.05, \uparrow<0.01$ compared to pair-fed. the proliferative compartment and $\left[{ }^{3} \mathrm{H}\right]$ thymidine labeling index. These findings suggest that infection had a greater impact on the ileum than other regions of the small intestine. The mucosal thymidine kinase activity is in keeping with this interpretation. Activity of this enzyme was increased only in the ileum in infected animals. Thus while decreased food intake resulted in a hypoproliferative state, YE infection resulted in a hyperproliferative state, which was particularly apparent in the ileum.

The decreased disaccharidase activities seen in the infected, but not the pair-fed, group can be attributed to a direct effect of the organism. The mechanism of brush border injury, however, is unclear. A number of mechanisms may be responsible for the observed changes. The degree of disaccharidase damage was out of proportion to the degree of mucosal injury demonstrated by histologic studies, at least in the proximal and mid-small intestine. Loss of villi alone does not appear to account for the degree of disaccharidase impairment. Furthermore, despite persistent histologic damage, maltase and sucrase levels returned to normal levels by day 14 in the proximal intestine.

In viral enteritis delayed maturation of enterocytes with immature crypt-like cells on the villi appear to be the explanation for alterations in mucosal enzymes (22). The small intestine in viral enteritis is characterized by decreased activities of disaccharidases and $\mathrm{Na}^{+} \mathrm{K}^{+}$ATPase, markers of mature enterocytes $(23,24)$, and increased thymidine kinase, a marker of crypt epithelium (24). While there was evidence of crypt proliferation and a severe reduction in disaccharidase activities in YE-infected animals, $\mathrm{Na}^{+} \mathrm{K}^{+}$ATPase was increased rather than decreased in all regions of the small intestine and thymidine kinase was increased only in the ileum. This suggests that while Yersinia causes increased cell production, it does not result in delayed cell maturation, at least in the proximal and mid-small intestine. An alternate explanation is direct brush border injury by metabolic products of the organism, a mechanism that has been described in the bacterial overgrowth syndrome $(25,26)$. Increased degradation of brush border glycoproteins was found to be due to the action of proteases released by the bacteria (26). In that study, as well as in ours, there was no histologic evidence of attachment of the bacteria to enterocytes.

In summary, weanling rabbits infected with YE develop diarrhea and weight loss. While the weight loss can be attributed primarily to decreased food intake, the histologic changes and diffuse brush border injury are due to infection by the organism. The loss of mucosal surface area and diffuse brush border injury could result in maldigestion and malabsorption of nutrients contributing to the diarrhea in this disease.

Table 2. Mucosal enzyme activities ${ }^{a}$

\begin{tabular}{|c|c|c|c|c|c|}
\hline & & Sucrase & Maltase & $\mathrm{Na}^{+} \mathrm{K}^{+}$ATPase & Thymidine kinase \\
\hline \multirow[t]{3}{*}{ Proximal } & $\mathrm{C}$ & $85 \pm 10$ & $260 \pm 24$ & $3.3 \pm 0.3$ & $4.7 \pm 0.6$ \\
\hline & $\mathrm{PF}$ & $90 \pm 11$ & $282 \pm 23$ & $3.0 \pm 0.3$ & $5.2 \pm 1.0$ \\
\hline & 1 & $22 \pm 4(* *, \ddagger)$ & $81 \pm 11\left({ }^{* *} \ddagger\right)$ & $4.0 \pm 0.2(*, \dagger)$ & $3.3 \pm 0.6$ \\
\hline \multirow[t]{3}{*}{ Mid } & $\mathrm{C}$ & $78 \pm 7$ & $241 \pm 26$ & $3.5 \pm 0.4$ & $3.4 \pm 0.5$ \\
\hline & $\mathrm{PF}$ & $76 \pm 12$ & $260 \pm 45$ & $3.1 \pm 0.4$ & $4.6 \pm 0.6$ \\
\hline & I & $24 \pm 3\left({ }^{* *} \ddagger\right)$ & $98 \pm 14(* * *)$ & $4.6 \pm 0.4(* *,+)$ & $4.6 \pm 0.7$ \\
\hline \multirow[t]{3}{*}{ Ileum } & $\mathrm{C}$ & $69 \pm 10$ & $203 \pm 24$ & $3.2 \pm 0.2$ & $4.6 \pm 0.5$ \\
\hline & PF & $66 \pm 7$ & $196 \pm 28$ & $3.6 \pm 0.3$ & $5.6 \pm 0.8$ \\
\hline & $\mathrm{I}$ & $10 \pm 3(* *+)$ & $39 \pm 13(* *+)$ & $5.6 \pm 0.5(* *,+)$ & $12.8 \pm 3.5(* *, \dagger)$ \\
\hline \multirow[t]{3}{*}{ Colon } & $\mathrm{C}$ & & & $7.6 \pm 1.1$ & $6.2 \pm 0.2$ \\
\hline & $\mathrm{PF}$ & & & $5.1 \pm 0.7$ & $10.9 \pm 3.2$ \\
\hline & I & & & $6.2 \pm 0.8$ & $7.1 \pm 0.5$ \\
\hline
\end{tabular}

${ }^{a}$ Mucosal enzyme activities in C (controls), PF (pair-fed), and I (infected) animals 6 days after inoculation. Sucrase and maltase are expressed as $\mathrm{U} / \mathrm{g}$ protein and $\mathrm{Na}^{+} \mathrm{K}^{+} \mathrm{ATPase}$ and thymidine kinase as $\mathrm{U} / \mathrm{mg}$ protein. Values are mean $\pm \mathrm{SE}$.

${ }^{*} p<0.05,{ }^{* *} p<0.01$ compared to controls, $\dagger p<0.05, \ddagger p<0.01$ compared to pair-fed. 
Acknowledgments. The authors thank G. Meyers and A. Buret for technical assistance and $\mathrm{R}$. Funk for typing the manuscript.

\section{REFERENCES}

1. Kohl S 1979 Yersinia enterocolitica infections in Children. Pediatr Clin North Am 26:433-443

2. Maki M, Vesikari J, Rantala I, Gronroos P 1980 Yersiniosis in children. Arch Dis Child 55:861-865

3. Marks M, Pai C, Lafleur L, Lackman L, Hammerberg O 1980 Yersinia enterocolitica-gastroenteritis: a prospective study of clinical, bacteriologic and epidemiologic features. J Pediatr 96:26-31

4. Denneberg T, Friedberg M, Samuelsson T, Winblad S 1981 Glomerulonephritis in infections with Yersinia enterocolitica O-serotype-3. Acta Med Scand 209:97-101

5. Zink DL, Feeley JC, Wells JG, Vanderzant C, Vickery JC, Roof WD, O'Donovan GA 1980 Plasmid-mediated tissue invasiveness in Yersinia enterocolitica. Nature (Lond) 283:224-226

6. Gemski P, Lazere JR, Casey T 1980 Plasmid associated with pathogenicity and calcium dependency of Yersinia enterocolitica. Infect Immun 27:682685

7. Lian C-J, Pai CH 1985 Inhibition of human neutrophil chemiluminescence by plasmid-mediated outer membrane proteins of Yersinia enterocolitica. Infect Immun 49:145-151

8. Pai CH, DeStephano L 1982 Serum resistance associated with virulence in Yersinia enterocolitica. Infect Immun 35:605-61

9. Pai C, Mors V, Seemayer T 1980 Experimental yersinia enterocolitica enteritis in rabbits. Infect Immun 28:238-244

10. Bjerknes M, Cheng H 1981 The stem cell zone of the small intestinal epithelium. IV. Effects of resecting 30\% of the small intestine. Am J Anat 160:93103

11. Dahlquist A 1964 Method of assay of intestinal disaccharidases. Anal Biochem 7:18-25

12. Kelly M, Butler DG, Hamilton JR 1972 Transmissible gastroenteritis in piglets: a model of infantile viral diarrhea. J Pediatr 80:925-931
13. Klemperer $\mathrm{H}$, Haynes $\mathrm{G} 1968$ Thymidine kinase in rat liver during development. Biochem J 108:541-546

14. Lowry OH, Rosenbrough NJ, Farr AL, Randal RJ 1951 Protein measurement with the folin phenol reagent. J Biol Chem 193:265-275

15. Mariyama $T 1973$ Studies on biological characteristics and pathogenicity of Yersinia enterocolitica. II. Experimental infection in monkeys. Jpn J Bacteriol 28:413-421

16. Carter P 1975 Pathogenicity of Yersinia enterocolitica for mice. Infect Immun 11:164-170

17. Bradford W, Noce P, Gutman Z 1974 Pathologic features of enteric infection with Yersinia enterocolitica. Arch Pathol 98:17-22

18. Worthington N, O'Donnell K, Dowling J, Murphy T, Whitmore E 1984 Granulomatous hepatitis in Yersinia enterocolitica bacteremia. J Infect 9:170-173

19. Ryan M, Burke $P$, Novingen Q, Shah N 1979 Hepatic abscess due to Yersinia enterocolitica. Am J Dis Child 133:961-962

20. Viteri F, Schneider R 1974 Gastrointestinal alterations in protein calorie malnutrition. Med Clin North Am 58:1487-1505

21. Butzner JD, Butler DG, Miniats OP, Hamilton JR 1985 Impact of chronicprotein calorie malnutrition on small intestinal repair after acute viral enteritis: a study in gnotobiotic piglets. Pediatr Res 19:476-481

22. Shepherd R, Butler D, Cutz E, Gall DG, Hamilton J 1979 The mucosal lesion in viral enteritis. Extent and dynamics of the epithelial response to virus invasion in transmissible gastroenteritis of piglets. Gastroenterology 76:770777

23. Gall DG, Chapman D, Kelly M, Hamilton J $1977 \mathrm{Na}^{+}$transport in jejunal crypt cells. Gastroenterology 72:452-456

24. Weiser M 1973 Intestinal epithelial cell surface membrane glycoprotein synthesis. I. An indicator of cellular differentiation. J Biol Chem 248:25362541

25. Jonas A, Flanagan P, Forstner G 1977 Pathogenesis of mucosal injury in the blind loop syndrome. Brush border enzyme activity and glycoprotein degradation. J Clin Inv 60:1321-1330

26. Jonas A, Krishnan C, Forstner G 1978 Pathogenesis of mucosal injury in the blind loop syndrome. Release of disaccharidase from brush border membranes by extracts of bacteria obtained from intestinal blind loops in rats. Gastroenterology 75:791-795 